\title{
Extraction of Cellulose Acetate From Cajuput (Melaleuca leucadendron) Twigs and Sugarcane (Saccharum officinarum) Bagasse by Environmentally Friendly Approach
}

Roni Maryana ( $\sim$ roni.maryana@gmail.com )

Indonesian Institute of Sciences: Lembaga Ilmu Pengetahuan Indonesia https://orcid.org/0000-0001-7134-9347

\section{Muryanto Muryanto}

Indonesian Institute of Sciences: Lembaga IImu Pengetahuan Indonesia

\section{Eka Triwahyuni}

Indonesian Institute of Sciences: Lembaga IImu Pengetahuan Indonesia

\section{Oktaviani Oktaviani}

National Nuclear Energy Agency of Indonesia: Badan Tenaga Nuklir Nasional

\section{Hafiizh Prasetia}

Indonesian Institute of Sciences: Lembaga Ilmu Pengetahuan Indonesia

\section{Atanu Kumar Das}

Swedish University of Agricultural Sciences: Sveriges lantbruksuniversitet

\section{Yanni Sudiyani}

Indonesian Institute of Sciences: Lembaga IImu Pengetahuan Indonesia

\section{Research Article}

Keywords: cellulose acetate, cajuput twig, sugarcane bagasse, prehydrolysis, acetylation

Posted Date: July 16th, 2021

DOI: https://doi.org/10.21203/rs.3.rs-615964/v1

License: (c) (i) This work is licensed under a Creative Commons Attribution 4.0 International License. Read Full License

Version of Record: A version of this preprint was published at Waste and Biomass Valorization on October 19 th, 2021. See the published version at https://doi.org/10.1007/s12649-021-01610-y. 


\section{Abstract}

This study was carried out to investigate the extraction of cellulose acetate (CA) from cajuput (Melaleuca leucadendron) twigs and sugarcane (Saccharum officinarum) bagasse using an environmentally friendly method. At first, cellulose was extracted from cajuput twigs (CT) and sugarcane bagasse (SB) through prehydrolysis followed by soda $(\mathrm{NaOH})$ pulping and elemental chlorine-free (ECF) bleaching. Later, the extracted cellulose was acetylated using iodine (I) as a catalyst. The obtained CA was characterized by Fourier-transform infrared spectroscopy (FTIR), nuclear magnetic resonance (NMR), thermal gravimetric analysis (TGA), scanning electron microscope (SEM) and X-ray diffraction. FTIR and NMR analysis proved the replacement of free $\mathrm{OH}$ (hydroxyl) groups by acetyl groups. The degree of substitution (DS) showed the acetylation capability of cellulose extracted from CT and SB as well. The diameter of CA and its crystallinity index $(\mathrm{Crl})$ were measured by SEM and X-ray diffraction, respectively. The diameter of CA extracted from CT was approximately $10 \mu \mathrm{m}$ and it was approximately 20 to $30 \mu \mathrm{m}$ for SB. The Crl of the CA extracted from SB and CT was 75.6 and 60.2, respectively. Furthermore, the thermal gravimetric analysis showed that CA extracted from CT and SB was thermal resistance. Therefore, CT and SB will be potential alternative resources for CA production using the mentioned medthod.

\section{Highlights}

- Cellulose acetate was successfully synthesized from cajuput twigs and sugarcane bagasse.

- FTIR and 1H NMR analysis confirmed the synthesis of cellulose acetate.

- Extracted cellulose acetate was thermally stable and higher crystallinity.

- Degree of substitution (DS) confirmed the capability of easier acetylation.

- Environmentally friendly approach, i.e., prehydrolysis, iodine as catalyst showed suitability for the synthesis of cellulose acetate.

\section{Introduction}

The Research on the extraction of value added biomaterials from biomass is one of the top most interested areas for the scientists [1]-[4]. Cellulose, the most abundant component of biomass, has been known as the essential material for the production of textile fibers, cellulose derivatives, pharmaceuticals substances, food additives, etc. Cellulose derivative, namely, cellulose acetate (CA) or an ester of cellulose, is the most commercially used and widely applied in the industrial sectors. CA is an interesting and very useful material due to its large spectrum of utilities. The main applications of CA are in the field of food packaging, textile industries, gas separator membrane, ultrafiltration membrane, coating and bioplastics [5]-[12]. CA has also been applied in the military and defence area, such as for less-prone low vulnerability ammunition (LOVA) systems. CA has been reported as promising binders for LOVA gun propellant [13], [14].

Besides thermochemical and hydrolytic routes to transform biomass into useful fuels and chemical, the catalytic conversion by using chemicals is industrially attractive because its fastest conversion rate and controllable selectivity. $\mathrm{CA}$ is produced by introducing the acetyl group to the cellulose. Generally, acetic anhydride is used as an acetylating agent by using $\mathrm{H}_{2} \mathrm{SO}_{4}$ as a catalyst [15]. However, this strong acid is considered as less environmentally friendly among other catalysts because of its toxicity properties. In another study, $\mathrm{NaHSO}_{4}$ has been used as a catalyst to reduce $\mathrm{H}_{2} \mathrm{SO}_{4}$ and acetylation reaction temperature [16]. Meanwhile, Wu et al. (2004) have reported synthesis CA in the absence of any catalysts by using ionic liquids at room temperature [17]. Moreover, the use of iodine has been proposed for the esterification of corn starch and rice husk $(\mathrm{RH})$ [18]-[20]. On the other hand, the preparation of high- 
purity cellulose is an important step for CA production. Pretreatment is one of the key factors to separate cellulose from other components especially lignin and hemicellulose before the acetylation process. The biological pretreatment of biomass has been reported previously [21], [22]. Meanwhile, other methods, such as mechanical, thermal, and chemical pretreatments have been studied to purify cellulose [23]-[28]. Sodium hydroxide and elemental chlorine-free (ECF) bleaching agents are the most commonly used chemicals in the pulp and paper industries [29], [30].

Wood pulps are the most traditional source of cellulose for CA production [31]. However, deforestation issue causes shortage of wood supply. Therefore, alternative resources such as agricultural waste have been considered as potential source of cellulose. In Indonesia, there are abundant biomass resources that are especially generated from agro-industrial sectors. Cajuput twigs (CT) and sugarcane bagasse (SB) are the potential biomass resources among others. Indonesia produces 600 to 650 tons of cajuput oil in every year. After distillation, twigs and leaves are the leftovers. The calculated biomass potency from cajuput oil distillation mills is approximately $32,500-65,000$ ton/year [32], [33]. Additionally, the Indonesian Ministry of Agriculture reported that sugar production is approximately 2.5 million tons in 2019 from 0.5 million hectares of planted area [34]. In the mill, sugarcane is crushed to extract the juice, and the bagasse is the leftover and usually combusted in the boiler. However, the residue can be used as potential resource for biorefinery process. SB potency was approximately 10 million tons and was continuously increasing in 2019. Therefore, CT and SB can be potential resources for the synthesis of CA.

However, there is no recorded single study on CA synthesis from CT. Meanwhile, Candido et al. (2017) have extracted CA from SB using acid $\left(\mathrm{H}_{2} \mathrm{SO}_{4}\right)$ treatment and $\mathrm{H}_{2} \mathrm{SO}_{4}$ as a catalyst during acetylation [35]. In addition, prehydrolysis and lodine as a catalyst for acetylation during CA extraction have not studied until now. Therefore, the application of environmentally friendly approach for CA production from CA and SB is contemporary considering environmental issues. That is why this study has been conducted to characterize the CA obtained from CT and SB through prehydrolysis treatment followed by soda $(\mathrm{NaOH})$ pulping, ECF bleaching and acetylation using iodine as a catalyst. Furthermore, the extracted CA has been compared with commercial CA.

\section{Materials And Methods}

\section{A Preparation of raw materials}

CT and SB were sourced from the cajuput oil mill and sugarcane mill, respectively, Yogyakarta, Indonesia. At first, CT and SB were washed and sun-dried to obtain a moisture content of around $10 \%$. Dried CT and SB were then cut into $0.5-1.0 \mathrm{~cm}$ in length. At last, CT and SB samples were air-dried for 3 days at $20 \pm 2^{\circ} \mathrm{C}$ to obtain a moisture content of approximately 8-10\%. For analytical purposes, CT and SB samples was ground to 40-80 mesh by a grinder (). Standard CA with average Mn 30,000 by GPC was obtained from Aldrich chemistry, and commercial pure cellulose C6228 was collected from Merck. Laboratory grade 100\% acetic acid (glacial) ( $\mathrm{CH} 3 \mathrm{COOH})$, iodine (I), 95-97\% sulfuric acid $\left(\mathrm{H}_{2} \mathrm{SO}_{4}\right), 99 \%$ sodium hydroxide $(\mathrm{NaOH}), 99 \%$ sodium thiosulfate pentahydrate $\left(\mathrm{Na}_{2} \mathrm{~S}_{2} \mathrm{O}_{3} \cdot 5 \mathrm{H}_{2} \mathrm{O}\right)$ and $99 \%$ sodium hydrogen sulfate monohydrate $\left(\mathrm{NaHSO}_{4} \cdot \mathrm{H}_{2} \mathrm{O}\right)$ reagents were supplied by Merck but $98 \%$ acetic anhydride $\left(\left(\mathrm{CH}_{3} \mathrm{CO}\right)_{2} \mathrm{O}\right)$ reagent was delivered by ajax chemicals.

\section{B Cellulose extraction}

\section{B.1 Prehydrolysis}

Prehydrolysis of CT and SB were done in a stainless-steel reactor having $255 \mathrm{~mm}$ in height and $76 \mathrm{~mm}$ in diameter at $150 \pm 2{ }^{\circ} \mathrm{C}$ for $2 \mathrm{~h}$. Distilled water was used for prehydrolysis and solid-to-liquid ratio was 1:12 for both types of materials. The solid residue was filtered for pulping. 


\section{B.2 Pulping}

Soda pulping of CT and SB were conducted using same reactor as used in prehydrolysis. In pulping process, solid to liquor ratio was $1: 7$, and $10 \%(\mathrm{w} / \mathrm{w} \%)$ of $\mathrm{NaOH}$ was used. The pulping temperature and time were $150{ }^{\circ} \mathrm{C}$ and $2 \mathrm{~h}$, respectively. Black liquor was removed, and the pulps were washed properly to remove all $\mathrm{NaOH}$.

\section{B.3 Bleaching}

The chemical ECF bleaching for CT and SB pulps was carried out separately in two stages in Erlenmeyer flask. In the first stage, pulps were mixed with $0.5 \%(\mathrm{w} / \mathrm{v}) \mathrm{NaClO} 2$ and $0.5 \mathrm{ml} \mathrm{CH} 3 \mathrm{COOH}$. The bleaching conditions were solid to liquor ratio $1: 12, \mathrm{pH} 2-3$, temperature $80^{\circ} \mathrm{C}$ and time $90 \mathrm{~min}$. After the first stage, the pulps were filtrated and washed with distilled water until the $\mathrm{pH}$ reached a value of 7 . In the last stage, the pulps were mixed with $10 \%$ (v/v) H2O2 for $90 \mathrm{~min}$ at $70^{\circ} \mathrm{C}$ under the solid to liquor ratio of 1:12. At the end of this stage, pulps were filtered and washed until the $\mathrm{pH}$ value was 7.

\section{Cellulose acetate synthesis}

The synthesis of CA from CT and SB cellulose was done separately in a $250 \mathrm{ml}$ Erlenmeyer flask. For CA synthesis, $1 \mathrm{~g}$ of each type of cellulose was mixed with $50 \mathrm{ml}$ acetic anhydride and $1.5 \mathrm{~g}$ iodine, and the mixture was stirred at $100^{\circ} \mathrm{C}$ for $5 \mathrm{~h}$. subsequently, sodium thiosulfate pentahydrate was added to the mixture and stirred until the color changed. Then, the mixture temperature was lowered to room temperature $\left(25^{\circ} \mathrm{C}\right)$ and $150 \mathrm{ml}$ ethanol was added and stirred for $60 \mathrm{~min}$. After that, the solid residue was filtrated and washed by $75 \%(\mathrm{v} / \mathrm{v})$ ethanol and distilled water until the $\mathrm{pH} 7$. At the end of the process, the residue was dissolved in the dichloromethane for $60 \mathrm{~min}$ at room temperature, and the residue was then filtrated to obtain $\mathrm{CA}$.

\section{Characterization}

\section{D.1 Raw materials}

\section{D.1.1 Chemical analyses}

Chemical analysis of CT and SB materials were performed. Acid-insoluble lignin was examined using T 222 om-11. Meanwhile, acid-soluble lignin was determined according to the method of UV-vis spectro-metric using wavelength $205 \mathrm{~nm}$ (TAPPI um 250). Extractive was measured as per the standard T $204 \mathrm{om}-88$. The sugar contents of raw material were analyzed by high-performance liquid chromatography waters e2695 after acid hydrolysis of extractive free samples at $120^{\circ} \mathrm{C}$ for $1 \mathrm{~h}$ using $72 \%$ sulfuric acid followed by $4 \%$ sulfuric acid. The analysis was done after filtering and diluting the samples.

\section{D.2 Extracted cellulose}

\section{D.2.1 Chemical analyses}

The chemical analysis for the extracted cellulose from CT and SB was done following the similar procedure described above for raw materials. However, the samples were used directly without any extractive extraction.

\section{D.3 Cellulose acetate}

\section{D.3.1 Functional groups}

Functional groups of extracted CA from CT and SB were studied by using Fourier transmission infrared (FTIR) spectroscopy IR Prestige 21 Shimadzu. The samples were blended with $\mathrm{KBr}$ followed by compressing this mixture in 
the sample disk. The used transmission wavenumber was in the range of $4000-400 \mathrm{~cm}^{-1}$. To compare the acetylation performance of this studied materials, functional groups of commercial CA and cellulose were studied by FTIR. For the furthermore confirmation of acetylation, the $1 \mathrm{H}$ nuclear magnetic resonance (NMR) was performed for CA of CT and SB. The NMR spectra were recorded on a Jeol $500 \mathrm{MHz}$ instrument, and chemical shifts were reported in parts per million from tetra methyl silane.

\section{D.3.2 Degree of substitution}

Degree of substitution (DS) was determined following the saponification reaction according to Zhou et al. (2016) [36]. For the determination of DS, $1 \mathrm{~g}$ of each type of CA sample was transferred to $250 \mathrm{ml}$ Erlenmeyer flask and $40 \mathrm{ml}$ of $75 \%\left(\mathrm{v} / \mathrm{v}\right.$ ) ethanol was then added in the flask. The mixture was heated at $60^{\circ} \mathrm{C}$ for $30 \mathrm{~min}$. Then, $50 \mathrm{ml} \mathrm{of} 0.5 \mathrm{~N} \mathrm{NaOH}$ was added in the mixture and heated at $60^{\circ} \mathrm{C}$ for $30 \mathrm{~min}$. the flask was tightly closed and left to stand at $25^{\circ} \mathrm{C}$ for 72 h. After that, the excess $\mathrm{NaOH}$ was titrated with $0.5 \mathrm{~N} \mathrm{HCl}$ using the indicator of phenolphthalein until the disappearance of pink color. After the $\mathrm{NaOH}$ titration, about $1 \mathrm{ml}$ of $\mathrm{HCl}$ was added in the mixture for overnight. In the next, back titration was conducted by $0.5 \mathrm{~N} \mathrm{NaOH}$ with the indicator of phenolphthalein until the appearance of faint pink color after vigorously shaking. The same procedure was applied for the blank sample. The percentage of acetyle (AC) and DS were calculated following the Eq. (1) and Eq. (2), respectively.

$$
A C(\%)=\frac{\left\lceil\left(V_{4}-V_{3}\right) N_{N a O H}+\left(V_{1}-V_{2}\right) N_{H C l}\right\rceil \times 4.305}{W}
$$

1

$$
D S=\frac{3.86 \times A C(\%)}{102.40-A C(\%)}
$$

2

Where $\mathrm{V}_{1}$ and $\mathrm{V}_{2}$ are required volume of $\mathrm{NaOH}$ for titration of the sample and he blank, respectively, $\mathrm{V} 3$ and $\mathrm{V} 4$ are required volume of $\mathrm{HCl}$ for titration of the sample and the blank, respectively, Normality of $\mathrm{NaOH}$ and $\mathrm{Normality}$ of $\mathrm{HCl}$ are the concentration of $\mathrm{NaOH}$ and $\mathrm{HCl}$, respectively, and $\mathrm{W}$ represents the weight of the sample.

\section{D.3.3 Crystallinity}

The crystallinity of extracted CA from CT and SB was performed by X-ray diffraction (XRD). A panalytical X-ray diffractometer with $\mathrm{Cu} \mathrm{Ka} 1.5405 \mathrm{~nm}$ radiation at $400 \mathrm{kV}$ and $300 \mathrm{~mA}$ was used to investigate the $\mathrm{X}$-ray diffraction spectra. This analysis was also done for commercial CA and cellulose to compare the crystallinity of extracted CA of this study. The crystallinity index (Crl) was calculated using the following equation:

$\mathrm{Crl}=100 \times\left[\left(I_{\max }-I_{\min }\right) / I_{\max }\right](3)$

Where $I_{\max }$ is the highest peak intensity of the crystalline fraction and Imin is the lowest intensity peak of the amorphous region.

\section{D.3.4 Thermal property}

Thermal Gravimetric Analysis (TGA) was used to analyze its thermal property. The heating rate was $10 \circ \mathrm{C} / \mathrm{min}$ maintaining the temperature range of 30-650 ○ C. A TA-Instruments SDT Q600 controlled the heating rate and 
temperature.

\section{D.3.5 Morphological properties}

The surfaces of the extracted CA from CT and SB were analyzed by using the scanning electron microscope (SU-3500 from Hitachi, Tokyo, Japan) with the magnification of $500 \times$ to $2500 \times$ magnification. The used voltage for imaging was $5 \mathrm{kV}$.

\section{Results And Discussion}

\section{A Characterization of raw materials and extracted cellulose}

The chemical composition of CT, SB and extracted cellulose from CT and SB has been presented in Table 1. The cellulose and hemicellulose content of SB material were higher than those of CT material. Conversely, the total lignin and water extractive contents of CT were higher than those of SB. Furthermore, after the delignification, the cellulose content of CT increased by $85.4 \%$, a little lower than that of SB that is $89.5 \%$. Delignification depends on the type and lignin content of raw materials [37]. Therefore, it was observed that the delignification of SB was easier than that of CT since the lignin content of CT was higher than that of SB. Meanwhile, regarding acid-insoluble lignin, the decreasing percentage of SB (75.9\%) was higher than that of CT (48.3\%). After the prehydrolysis and pulping, the remaining lignin in the pulps was removed via the ECF method using $\mathrm{NaClO}_{2}$ and $\mathrm{H}_{2} \mathrm{O}_{2}$. Hypochlorite preferentially destroys certain groups of lignin. Meanwhile, peroxides have been known to be effective bleaching agents and can improve brightness without significant yield loss [38]. On the other hand, prehydrolysis has great contribution to remove hemicellulose along with lignin [29]. Therefore, the cellulose content of CT and SB was increased after prehydrolysis followed by soda pulping and ECF bleaching. However, the remaining lignin content and hemicellulose content was higher for CT, which may need to consider by controlling prehydrolysis and pulping conditions along with bleaching conditions. Furthermore, the purity of cellulose of CT and SB was comparable to findings in previous studies. Cellulose content of date palm frond [39], oil palm empty fruit bunch (EFB) [40], rice straw [40] and SB [35] were 65.0 to 78.0, 72.4, 76.1 and $85.8 \%$, respectively. Therefore, the extracted cellulose from SB for this study was higher than date palm fronds and rice straw, while it was very close to SB observed in previous studies. On the other hand, purity of cellulose was in the range of date palm frond and lower than that of EFB and SB findings from other studies. This might be due to higher lignin content of CT raw material (35.20\%) compared to date palm frond (25.0\%) [39], EFB (28.1\%) [40], rice straw (11.5) [40] and SB (24.0\%) [35]. Interestingly, the delignification and CT (85.4\%) and SB (89.5\%) for this study was close to SB $(92 \%)$ obtained through acid treatment by other researchers. Thus, the prehydrolysis technique may reduce the chemical consumption leading to lowering the negative impact on the environment. 
Table 1

Chemical composition of raw materials and extracted cellulose

\begin{tabular}{|c|c|c|c|c|c|c|c|c|c|c|c|c|}
\hline & \multicolumn{6}{|c|}{ Raw material } & \multicolumn{6}{|c|}{ Extracted cellulose } \\
\hline & $\begin{array}{l}\text { Cajuput } \\
\text { twigs }\end{array}$ & & SD & $\begin{array}{l}\text { Sugarcane } \\
\text { bagasse }\end{array}$ & & SD & $\begin{array}{l}\text { Cajuput } \\
\text { twigs }\end{array}$ & & SD & $\begin{array}{l}\text { Sugarcane } \\
\text { bagasse }\end{array}$ & & SD \\
\hline Cellulose & 34.71 & \pm & 1.44 & 43.88 & \pm & 2.91 & 64.34 & \pm & 2.76 & 83.16 & \pm & 3.85 \\
\hline Hemicellulose & 13.63 & \pm & 0.78 & 19.65 & \pm & 1.41 & 11.56 & \pm & 1.06 & 2.73 & \pm & 0.93 \\
\hline $\begin{array}{l}\text { Acid insoluble } \\
\text { lignin }\end{array}$ & 31.90 & \pm & 1.27 & 22.85 & \pm & 2.74 & 16.48 & \pm & 1.02 & 5.49 & \pm & 0.92 \\
\hline $\begin{array}{l}\text { Acid soluble } \\
\text { lignin }\end{array}$ & 3. 30 & \pm & 0.11 & 2.12 & \pm & 0.18 & 1.80 & \pm & 0.28 & 0.30 & \pm & 0.07 \\
\hline $\begin{array}{l}\text { Water } \\
\text { extractive }\end{array}$ & 19.36 & \pm & 0.84 & 12.30 & \pm & 1.56 & - & & & - & & \\
\hline
\end{tabular}

\section{B Cellulose acetate characterization}

Figure 1 represents the IR spectra of CA of CT and SB, commercial cellulose and commercial CA. It was presented that there was neither stretching nor vibration of carbonyl ester at approximately $1730 \mathrm{~cm}-1$ for cellulose. Meanwhile, for commercial CA as well as CA of CT and SB, the peaks of carbonyl ester $(C=0)$ were clearly detected at this bandwidth. Das et al. (2014) and Filho et al. (2008) reported that the peak height of approximately $1728-1743 \mathrm{~cm}^{-1}$ is an indication of $\mathrm{C}=\mathrm{O}$ stretching of carbonyl ester band that is specific for acetyl groups [18], [41]. Therefore, the CA was extracted from CT and SB successfully.

During the acetylation, polar hydroxyl groups $(-\mathrm{OH})$ in the cellulose were substituted by acetyl groups $\left(-\mathrm{CH}_{3} \mathrm{COO}\right)$. In this study, the method of acetylation of CT and SB was different from the conventional CA production method, in which the acetylation of cellulose comprises activation, acetylation, and hydration steps. In this work, acetate anhydride and iodine were directly mixed with cellulose. Reportedly, iodine can form a complex with glucose polymers such as cellulose, and this reaction may help the solubility of cellulose in the acetic anhydride [42]. Biswas et al. (2009) have also shown that the acetylation and CA increase as a function of iodine concentration. The ratio of the iodine concentration to the pulp weight in this study was 1.5:1.

In addition, spectral studies of proton by NMR ( ${ }^{1} \mathrm{H}$ NMR) had also shown the proof of acetylation of CT and SB (Fig. 2). In the spectra of CA for CT, two dominants chemical shifts at $\delta 2.071$ and $\delta 2.040$ refer to acetyl- $\mathrm{CH}_{3}$ protons. On the other hand, only one acetyl- $\mathrm{CH}_{3}$ chemical shift was observed at $\delta 2.029$ for the spectra of CA of SB. These results confirm that CA was formed from each material. Moreover, CA extracted from CT may contain di-acetate because it has two chemical shifts. Meanwhile, CA extracted from SB may be dominated by mono-acetate and contained small portion of di-acetate.

\section{Degree of substitution}

Table 2 presents the DS and yield of the product. Theoretically, the DS for CA is 1, 2 and 3, for mono-acetate, di-acetate, and tri-acetate, respectively, which is corresponded to the hydroxyl group that could be acetylated. In this study, DS for CA of CT and CA of SB were 1.90 and 1.78, respectively. Both types of CA are close to DS 2 that is usually categorized as diacetate and could be the mix of mono-acetate and di-acetate. Das et al. (2014) have reported that the DS will be influenced by reaction conditions such as reactants concentration, time, and temperature [18]. In the reaction, carbonyl 
carbon of acetic anhydride is activated by iodine; subsequently, the oxygen from the hydroxyl group of cellulose attacks this carbonyl carbon resulting in sp3 hybridization [18], [19]. The yield of CA represents the weight of the product compared with that of initial cellulose (Table 2). It showed that yields were higher for both CT and SB acetylated celluloses. Compared with a previous study by Das et al. (2014), the DS for CA extracted from CT and SB were lower than that of rice husk $(\mathrm{RH})$. However, the yield of $\mathrm{RH}$ acetylated cellulose was lower than that of $\mathrm{CT}$ and SB. The temperature of reaction for CT and SB was $100^{\circ} \mathrm{C}$ that may result in a too fast acetylation rate when compared with reaction temperature of $80^{\circ} \mathrm{C}$ for $\mathrm{RH}$, and the $\mathrm{CA}$ nucleus cannot be formed further. Based on the DS value, extracted CA from CT and SB contain not only CA but also remaining cellulose that cannot be converted completely. In others previous studies, DS of CA extracted from date palm frond [39], EFB [40], rice straw [40], SB [35] and bamboo [43] were 1.02 to $3.01,0.84,0.21,2.52$ and 2.48 to 2.84 , respectively. The obtained results of DS for CT and SB were higher and lower than those of previous studies.

The obtained yield of CA for CT and SB were 89.3 and 99.3\%, respectively in this study. Barkalow et al. (1989) achieved 75.0-80.0\% yield of CA extracted from mechanical pulp [44]. Again, CA yield from RH was 66.0\% [18]. The CA yield for both types of materials (CT and SB) was higher than previous studies.

Table 2

Degree of substitution and yield of acetylated cellulose

\begin{tabular}{|c|c|c|c|c|c|c|c|}
\hline & cellulose to $\mathrm{I}_{2}$ ratio & Degree of substitution (DS) & & SD & Yield (\%) & & SD \\
\hline Cajuput twigs CA & 01:01.5 & 1.88 & \pm & 0.11 & 89.30 & \pm & 3.58 \\
\hline Sugarcane bagasse CA & 01:01.5 & 1.78 & \pm & 0.18 & 99.30 & \pm & 2.94 \\
\hline Rice husk* & 01:01.5 & 2.91 & & & 66.00 & & \\
\hline
\end{tabular}

*Das et al. 2014 [18]

\section{Thermal property}

From Fig. 3, the thermogravimetry analysis (TGA) of CA of CT and SB and commercial CA can be observed. There was a slight mass loss of approximately $5 \%$ up to $200^{\circ} \mathrm{C}$. It was less than finding of other researchers such as Filho et al., 2008; Candido et al., 2017 [35], [41]. This loss is corresponding to the loss of volatile compounds and $\mathrm{H}_{2} \mathrm{O}$ bound to the hydrophilic $(\mathrm{OH})$ groups of CA chains [45]. In the next stage, mass loss was $70-80 \%$ at $200-380^{\circ} \mathrm{C}$. It is the result of the pyrolytic decomposition of CA polymer chain followed by deacetylation along with the decomposition of lignin and hemicellulose chain [45]. The main thermal decomposition was occurred at $380-600^{\circ} \mathrm{C}$. It is due to the carbonization of CA [45]. Similar result was also obtained by other researcher where CA underwent major degradation between $330^{\circ} \mathrm{C}$ and $450^{\circ} \mathrm{C}$ [46]. The thermal degradation of CA obtained from CT and SB was more or less similar to commercial CA at first stage but it was higher than commercial CA in the second stage. The thermal degradation of CA obtained from SB and commercial CA showed similar amount of loss in the third stage while it was lower for CA obtained from CT (Fig. 3).

\section{E Crystallinity}

In Fig. 4, the sharp high-intensity peak at $2 \nabla=22^{\circ}$ describes the crystalline nature of cellulose and the Crl of cellulose was 86.6. After the acetylation, the Crl of the CA extracted from SB and CT was 75.6 and 60.2, respectively. Meanwhile, there was no peak detected at $2 \mathbb{Z}=22^{\circ}$ for commercial CA. It can be assumed that the crystallinity of cellulose 
decreased during the acetylation process. Moreover, the Crl of CA extracted from SB was higher than those of CA extracted from CT.

\section{F Morphological properties}

The morphologies of CA obtained from CT and SB were compared with those of cellulose. Figure 5 shows that the fiber diameter of acetylated cellulose of CT and SB were decreased compared with commercial cellulose. The diameter of commercial cellulose ranged from 26 to $29.9 \mu \mathrm{m}$. Meanwhile, diameter of CA extracted from CT and SB was approximately $10 \mu \mathrm{m}$ and it was 20 to $30 \mu \mathrm{m}$ for CA extracted from SB. Therefore, the acetylation process influences the structure of cellulose fibers.

Figure 5 SEM micrograph for commercial cellulose (a), cajuput twigs CA (b), and sugarcane bagasse CA (c)

\section{Conclusions}

Cellulose acetate (CA) was successfully synthesized from sugarcane bagasse (SB) and cajuput twigs (CT) through environmentally friendly approach. The prehydrolysis followed by soda pulping and acetylation using iodine as catalyst showed suitability to extract CA from CT and SB. The synthesized CA from CT and SB was confirmed by its FTIR and 1H NMR spectra. Thermal property, crystallinity index and morphologica properties of CA extracted from CT and SB showed better performance compared to commercial CA. Degree of substitution (DS) showed the suitability of acetylation of extracted cellulose from CT and SB as well. DS of CA for CT and SB was in the range of values observed in previous studies. On the other hand, the CA yield of CT and SB was higher than previous studies. Therefore, the use of prehydrolysis and iodine as a catalysis instead of $\mathrm{H}_{2} \mathrm{SO}_{4}$ for the production of $\mathrm{CA}$ can reduce the environmental pollution. Further study is needed to apply this approach to extract CA from other raw materials.

\section{Declarations}

\section{Author Contributions}

R.M. is main contributor and corresponding author, conceptualized the study, performed pretreatment and study analysis result for HNMR and SEM, while M, ET and HP performed the other experiments. O.O. and A.K.D. had revised and finalized it. YS supervised the study.

\section{Conflicts of interest}

There are no conflicts to declare

\section{Ethical approval}

This article does not contain any studies with human participants or animals performed by any of the authors.

\section{Acknowledgements}

The authors acknowledge the Ministry of Research, Technology, and Higher Education of The Republic of Indonesia for the research grant Incentive Research National Innovation System batch I, 2019.

Statement of Novelty. The research was undertaken to intensify agroindustrial waste for cellulose acetate production. The impact of this research not only beneficial to the farmers, but also industrial sectors such as cajuput oil extraction mill, sugar mill and CA factories. We report for the first time that cellulose acetate (mono- and di-acetate) was 
successfully produced from cajuput twigs. We believe that our study makes a significant contribution to the literature because the methods are applicable and promising for cellulose acetate production from agricultural biomass waste (cajuput twigs and sugercane bagasse). Furthermore, we notify the preparation of cellulose acetate by using an iodine catalyst that is more environmentally friendly than sulfuric acid, in a heterogeneous medium. The utilization of waste will also support sustainable agricultural development in the near future.

\section{References}

1. Maraveas, C.: "Production of Sustainable and Biodegradable Polymers from Agricultural Waste," Polymers (Basel)., 2020, doi:10.3390/polym12051127

2. Maraveas, C.: "Production of Sustainable Construction Materials Using Agro-Wastes," Materials (Basel)., 2020

3. Andrade, M.F., Colodette, J.L.: Dissolving pulp production from sugar cane bagasse. Ind. Crops Prod. 52, 58-64 (2014). doi:https://doi.org/10.1016/j.indcrop.2013.09.041

4. Hu, G., Heitmann, J.A., Rojas, O.J.: Feedstock pretreatment strategies for producing ethanol from wood, bark, and forest residues. BioResources. 3(1), 270-294 (2008). doi:10.15376/biores.3.1.270-294

5. Katrin, J., Bhat, R.: "Valorization of food processing wastes and by-products for bioplastic production," Sustain. Chem. Pharm., 18, 2020, doi:10.1016/j.scp.2020.100326

6. Najafi, M., Sadeghi, M., Bolverdi, M., Chenar, A., Mahdi, P., Pakizeh, "Gas permeation properties of cellulose acetate / silica nanocomposite membrane," Adv. Polym. Technol., no. September: 2016, pp. 1-10, 2017, doi:

10.1002/adv.21862

7. Kumar, S.S., Kumar, V.K., Kishore, K.K.: P V, “Investigation of the impact of cellulose acetate coating on the release pattern of freely soluble drug: metoprolol succinate. Res. J. Pharm. 6(4), 249-255 (2015)

8. E. et al Flores-López, Caloca, L.Z., Rogel-Hernández, J.: Development of an enantioselective membrane from cellulose acetate propionate/cellulose acetate for the separation of trans-stilbene oxide. Cellulose. 21, 1987-1995 (2014). doi:https://doi.org/10.1007/s10570-014-0252-0

9. Gemili, S., Yemenicioglu, A., Altinkaya, S.A.: Development of cellulose acetate based antimicrobial food packaging materials for controlled release of lysozyme. J. Food Eng. 90, 453-462 (2009).

doi:10.1016/j.jfoodeng.2008.07.014

10. Duarte, A.P., Cidade, M.T., Bordado, J.C.: “Cellulose Acetate Reverse Osmosis Membranes: Optimization of the Composition,” J. Appl. Polym. Sci., 2-8, 2005, doi:10.1002/app.23237

11. Reddy, N., Yang, Y.: “Biofibers from agricultural byproducts for industrial applications," Trends Biotechnol., 23, 1, 2005, doi:10.1016/j.tibtech.2004.11.002

12. Luck, W.A.P., Rangsriwatananon, K.: The structure of adsorbed water in cellulose acetate membranes. Colloid Polym. Sci. 1026, 1018-1026 (1997)

13. Sanghavi, R.R., Kamale, P.J., Shaikh, M.A.R., Chakraborthy, T.K., Asthana, S.N., Singh, A.: Glycidyl azide polymerbased enhanced energy LOVA gun propellant. Def. Sci. J. 56(3), 407-416 (2006). doi:10.14429/dsj.56.1907

14. Pillai, A.G.S., Joshi, M.M., Barve, A.M., Velapure, S.P., Karir, J.S.: Cellulose acetate binder-based LOVA gun propellant for tank guns. Def. Sci. J. 49(2), 141-149 (1999). doi:10.14429/dsj.49.3799

15. Cerqueira, D.A., Filho, G.R., Meireles, S.: Optimization of sugarcane bagasse cellulose acetylation. Carbohydr. Polym. 69, 579-582 (2007). doi:10.1016/j.carbpol.2007.01.010

16. Djuned, F.M., Asad, M., Ibrahim, M.N.M., Daud, W.R.W., "Synthesis and characterization of cellulose acetate from TCF oil palm empty fruit bunch pulp," BioResources, vol. 9, no. 3, pp. 4710-4721, 2014, doi:

10.15376/biores.9.3.4710-4721

Page 10/16 
17. Wu, J., Zhang, J., Zhang, H., He, J., Ren, Q., Guo, M.: “Homogeneous Acetylation of Cellulose in a New lonic Liquid,” Biomacromolecules, pp. 266-268, 2004

18. Das, A.M., Ali, A.A., Hazarika, M.P.: Synthesis and characterization of cellulose acetate from rice husk: Eco-friendly condition. Carbohydr. Polym. 112, 342-349 (2014). doi:10.1016/j.carbpol.2014.06.006

19. Biswas, A., Shogren, R.L., Willett, J.L.: Solvent-free process to esterifypolysaccharides. Biomacromol. 6, 18431845 (2005). doi:https://doi.org/10.1021/bm0501757

20. Yadollahi, R., et al.: How properties of cellulose acetate films are affected by conditions of iodine-catalyzed acetylation and type of pulp. Cellulose 26, 6119-6132 (2019)

21. Sharma, H.K., Xu, C., Qin, W.: Biological Pretreatment of Lignocellulosic Biomass for Biofuels and Bioproducts: An Overview. Waste Biomass Valoriz. 10(2), 235-251 (2019). doi:10.1007/s12649-017-0059-y

22. Singh, M., Mathur, N., Tuli, A.S., Gupta, D.K., Barrow, R.P., Puri, C.J.: “Cellulosic ethanol production via consolidated bioprocessing by a novel thermophilic anaerobic bacterium isolated from a Himalayan hot spring," Biotechnol. Biofuels, 10, 73, 2017, doi: doi:10.1186/s13068-017-0756-6

23. Chen, J., Adjallé, K., Barnabé, S., Perrier, M., Paris, J.: "Mechanical and Thermal Pretreatment Processes for Increasing Sugar Production from Woody Biomass Via Enzymatic Hydrolysis," Waste Biomass Valoriz., 0123456789, 2018, doi:10.1007/s12649-018-0217-x

24. Septevani, A.A., Burhani, D., Sampora, Y., Devy, Y.A., Novi, G., "The Effect of Acid Hydrolysis Treatment on the Production of Nanocellulose Based on Oil Palm Empty Fruit Bunches," J. Kim. Terap. Indones., vol. 21, no. June, pp. 31-37, 2019

25. Maryana, R., Nakagawa-izumi, A., Kajiyama, M., Ohi, H.: Environment-Friendly Non-Sulfur Cooking and Totally ChlorineFree Bleaching for Preparation of Sugarcane Bagasse Cellulose. J. Fiber Sci. Technol. 73(8), 182-191 (2017). doi:10.2115/fiberst.2017-0025

26. Jacquet, A., Maniet, N., Vanderghem, G., Delvigne, C., Richel, F.: Application of steam explosion as pretreatment on lignocellulosic material: a review. Ind. Eng. Chem. Res. 54(10), 2593-2598 (2015)

27. Grigatti, M., Montecchio, D., Francioso, O., Ciavatta, C.: "Structural and Thermal Investigation of Three Agricultural Biomasses Following Mild-NaOH Pretreatment to Increase Anaerobic Biodegradability," Waste Biomass Valoriz., 1135-1148, 2015, doi:10.1007/s12649-015-9423-y

28. Kaur, R., Uppal, S.K.: "Structural characterization and antioxidant activity of lignin from sugarcane bagasse," Colloid Polym. Sci., 2015, doi:10.1007/s00396-015-3653-1

29. Das, A.K., Nakagawa-izumi, A., Ohi, H.: "Quality Evaluation of Dissolving Pulp Fabricated from Banana Plant Stem and Its Potential for Biorefinery," Carbohydr. Polym., 2016, doi:10.1016/j.carbpol.2016.03.103

30. Das, A.K., Nakagawa-izumi, A., Ohi, H.: “Evaluation of Pulp Quality of Three Non-Wood Species as Alternative Raw Materials for Paper Production," Japan Tappi, vol. 69, 2015

31. Jiang, X., Bai, Y., Chen, X., Liu, W.: A review on raw materials, commercial production and properties of lyocell fiber. J. Bioresour. Bioprod. 5(1), 16-25 (2020). doi:10.1016/j.jobab.2020.03.002

32. Agrolndonesia, “Menuju swasembada minyak kayu putih nasional,”: 2019. http://agroindonesia.co.id/2019/12/menuju-swasembada-minyak-kayu-putih-nasional/ (accessed Mar. 04, 2020)

33. Rimbawanto, P., Kartikawati, A. NK, Minyak Kayu Putih, dari tanaman asli Indonesia untuk Masyarakat Indonesia. Yogyakarta, 2017

34. Hendaryati, D.D., Arianto, Y., "Tree Crop Estate Statistics of Indonesia 2017-2019," Ministry of Agriculture of Republic Indonesia, 2019. https://drive.google.com/file/d/1akvyga1K8-5-4RyWiG7X9tS4RPG6MgPP/view (accessed Jan. 22, 2021)

Page $11 / 16$ 
35. Candido, R.G., Godoy, G.G., Gonçalves, A.: Characterization and application of cellulose acetate synthesized from sugarcane bagasse. Carbohydr. Polym. 167, 280-289 (2017). doi:10.1016/j.carbpol.2017.03.057

36. Zhou, X., et al.: Effect of the degree of substitution on the hydrophobicity of acetylated cellulose for production of liquid marbles. Cellulose. 23, 811-821 (2016). doi:10.1007/s10570-015-0856-z

37. Gomes, V.J., Jameel, H., Chang, H.M., Narron, R., Colodette, J., Hart, P.W.: "Effects of lignin chemistry on oxygen delignification performance, TAPPI JOURNAL July 2018," TAPPI J., no. July, 2018, doi:10.32964/TJ17.07.373

38. Smook, G.: Handbook for pulp and paper technologist, 7th edn. Canadian Pulp and Paper Association, Quebec (1989)

39. Jassem, A.S., M. Sh.K., and "CELLULOSE ACETATE PRODUCTION BY, M.A.H.: ACETYLATION OF CELLULOSE CELLULOSE ACETATE PRODUCTION BY ACETYLATION OF CELLULOSE DERIVED FROM DATE PALM FRONDS," Iraqi J. Agric. ciences, no. July, 2020

40. Maryana, R., Anwar, M., Hasanah, S.U., Fitriana, E., Suwanto, A., Rizal, W.A.: “Cellulose acetate production from paddy rice straw and oil palm empty fruit bunch: trichloroacetate catalyst Cellulose acetate production from paddy rice straw and oil palm empty fruit bunch : trichloroacetate catalyst," IOP Conf. Ser. Earth Environ. Sci., 462, 2020, doi:10.1088/1755-1315/462/1/012054

41. Rodrigues Filho, G., et al.: Synthesis and characterization of cellulose acetate produced from recycled newspaper. Carbohydr. Polym. 73(1), 74-82 (2008). doi:10.1016/j.carbpol.2007.11.010

42. Biswas, A., Selling, G.S., Shogren, R.L., Willett, J.L., Buchanan, C.M., Cheng, H.N.: lodine-catalyzed esterification of polysaccharides. Chem. Today 27(4), 33-35 (2009)

43. Cai, J., Fei, P., Xiong, Z., Shi, Y., Yan, K., Xiong, H.: Surface acetylation of bamboo cellulose: Preparation and rheological properties. Carbohydr. Polym. 92(1), 11-18 (2013). doi:10.1016/j.carbpol.2012.09.059

44. Barkalow, D.G., Rowell, R.M., Young, R.A.: A new approach for the production of cellulose acetate: Acetylation of mechanical pulp with subsequent isolation of cellulose acetate by differential solubility. J. Appl. Polym. Sci. 37(4), 1009-1018 (1989). doi:10.1002/app.1989.070370414

45. Hamid, S., Kiran, V.P., N. G, and Varma, A.: “Utilization of sugarcane bagasse cellulose for producing cellulose acetates: Novel use of residual hemicellulose as plasticizer," Carbohydr. Polym., vol. 76, 2009

46. Arthanareeswaran, G., Thanikaivelan, P., Srinivasn, K., Mohan, D., Rajendran, M.: Synthesis, characterization and thermal studies on cellulose acetate membranes with additive. Eur. Polym. J. 40(9), 2153-2159 (2004).

doi:10.1016/j.eurpolymj.2004.04.024

\section{Figures}




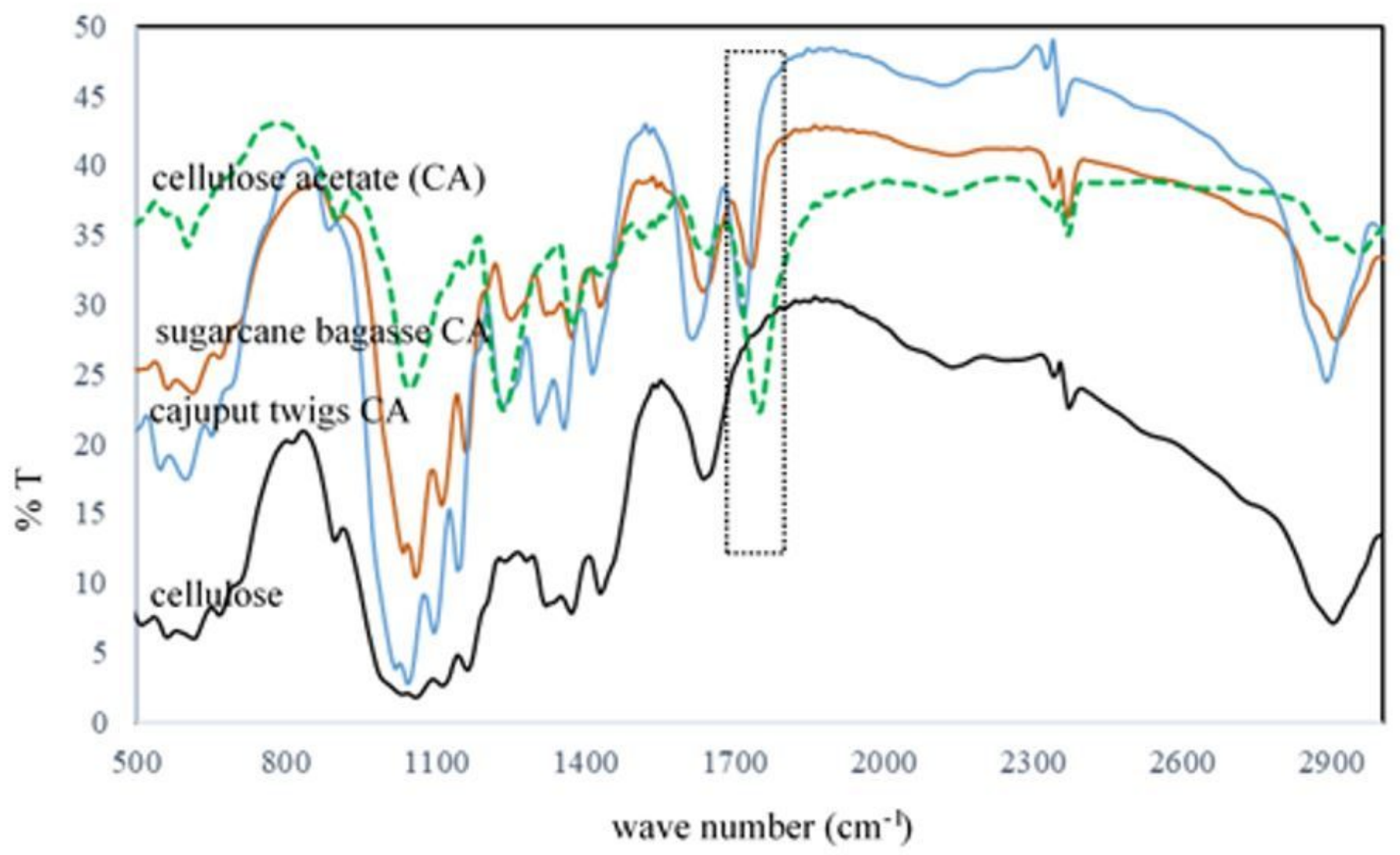

Figure 1

IR spectra of cellulose, cajuput twigs CA, sugarcane bagasse CA, and commercial CA
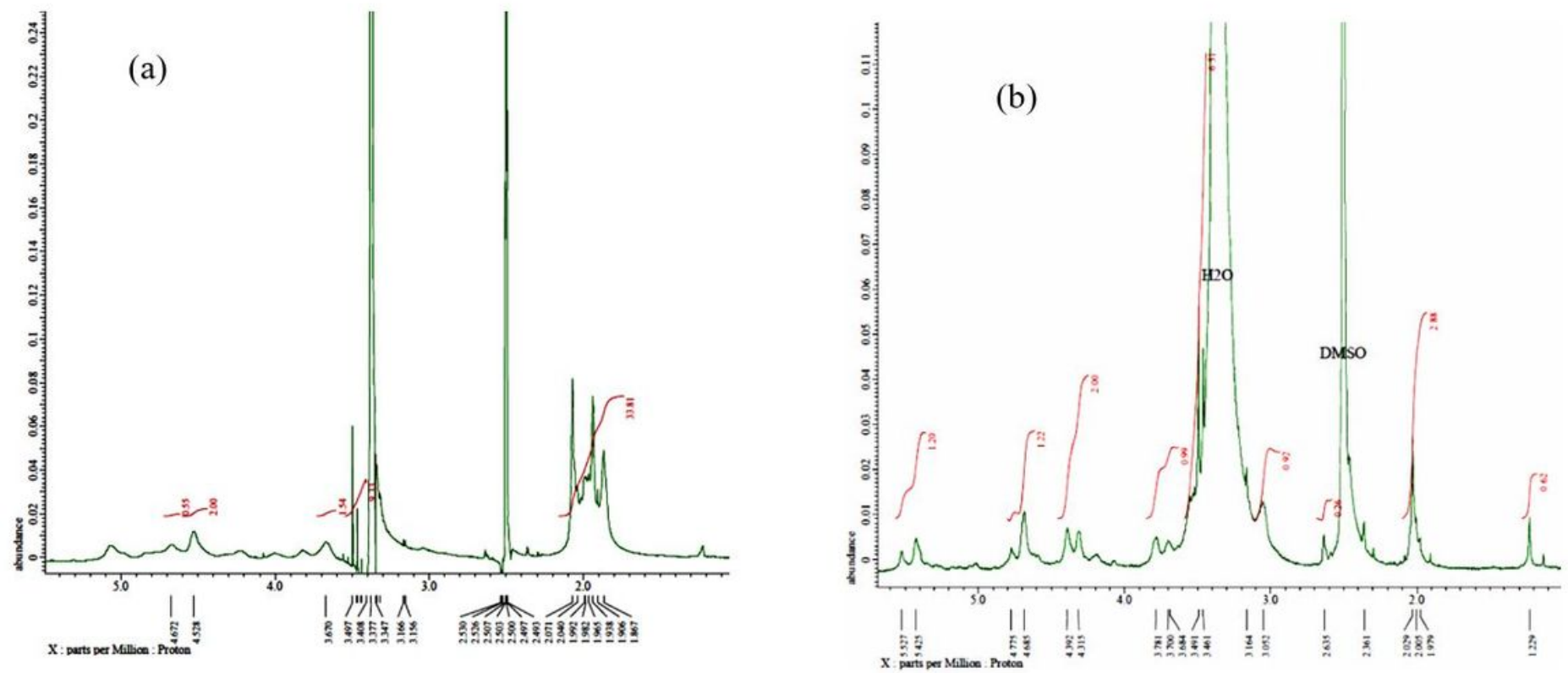

Figure 2

1H NMR spectrum of cajuput twigs CA (a) and sugarcane bagasse CA (b) 


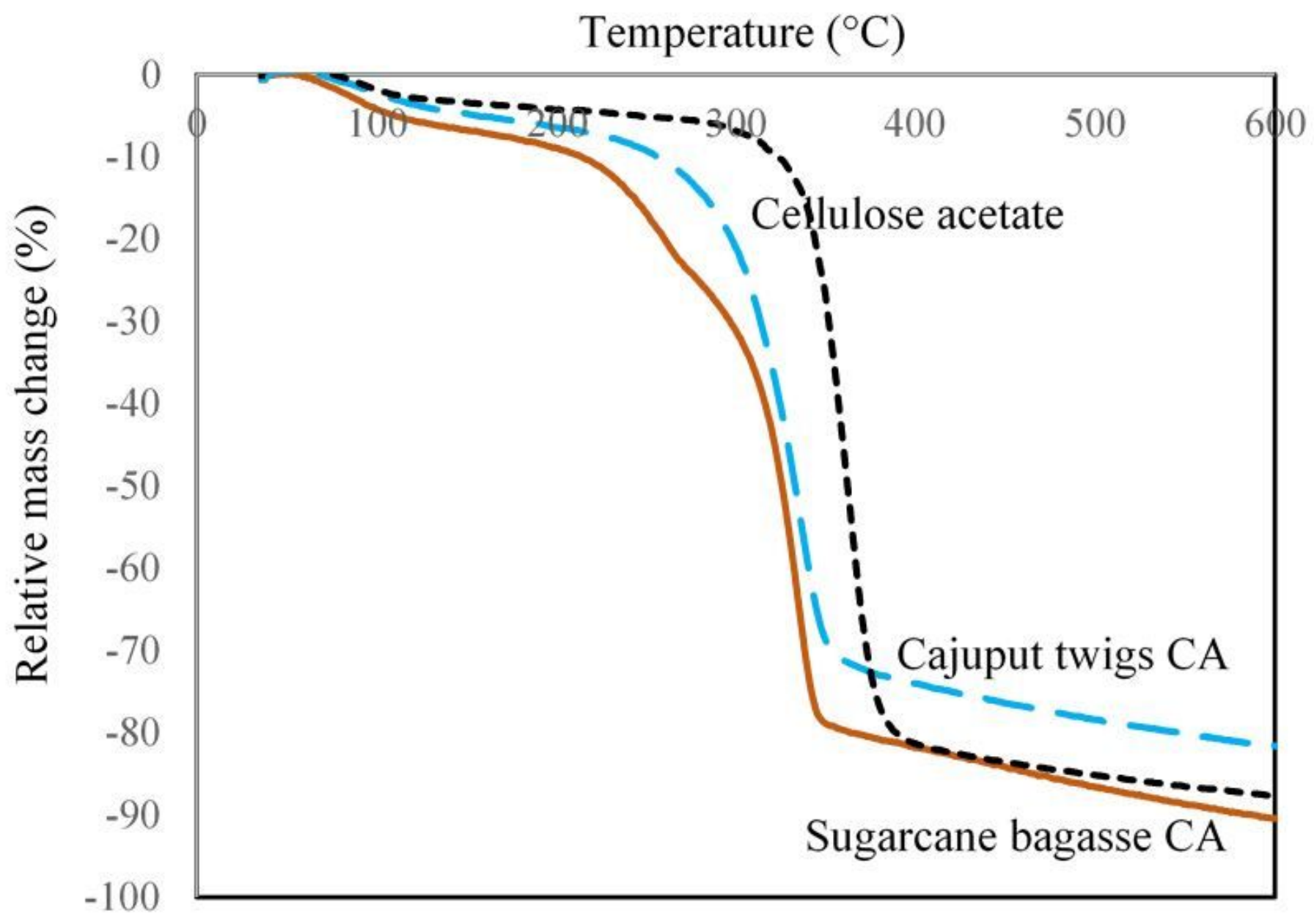

Figure 3

Thermogravimetric analysis curves for commercial cellulose acetate, cajuput twigs CA, and sugarcane bagasse CA 


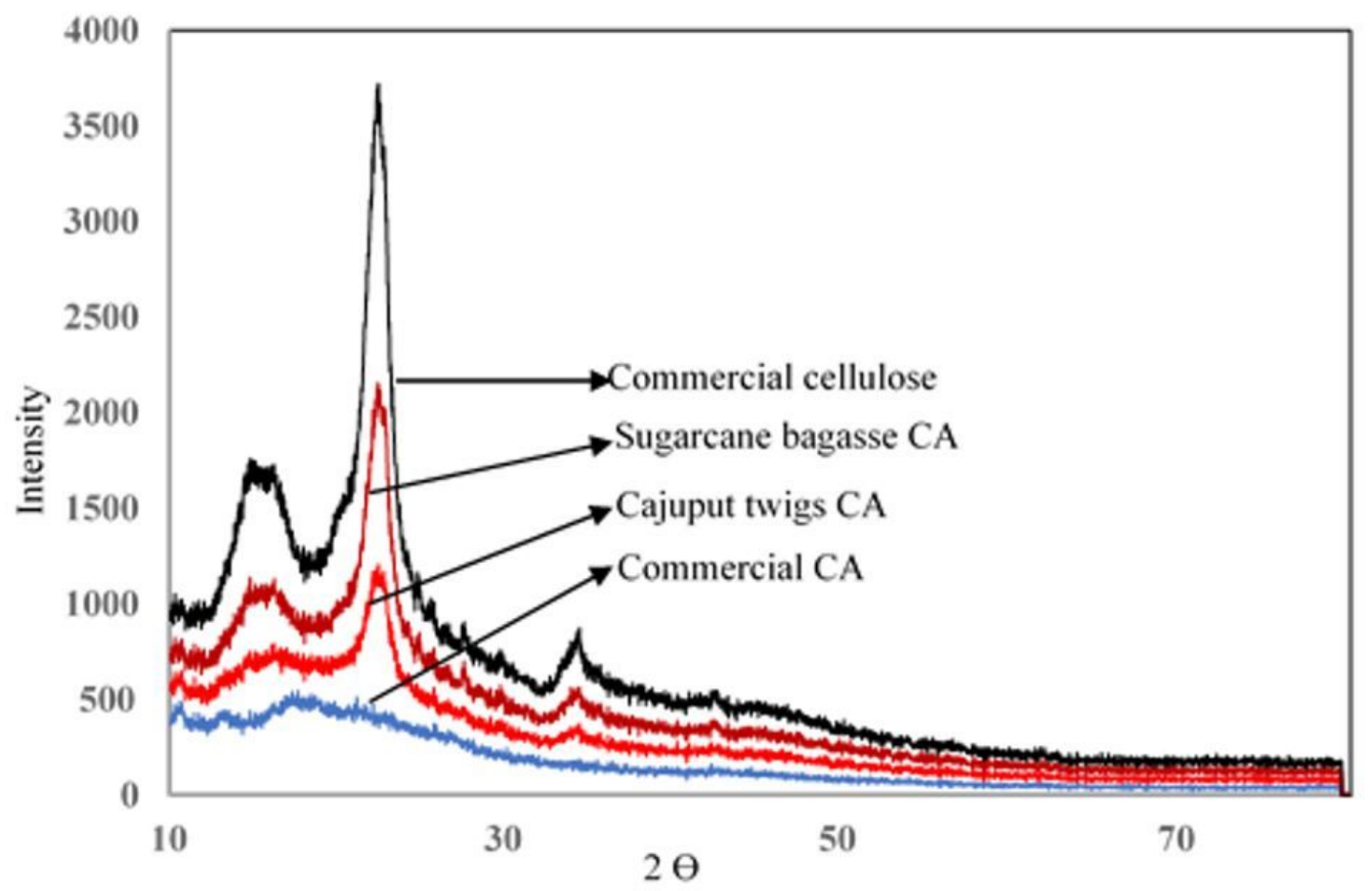

Figure 4

X-ray diffraction spectra for commercial cellulose, sugarcane bagasse CA, cajuput CA, and commercial CA

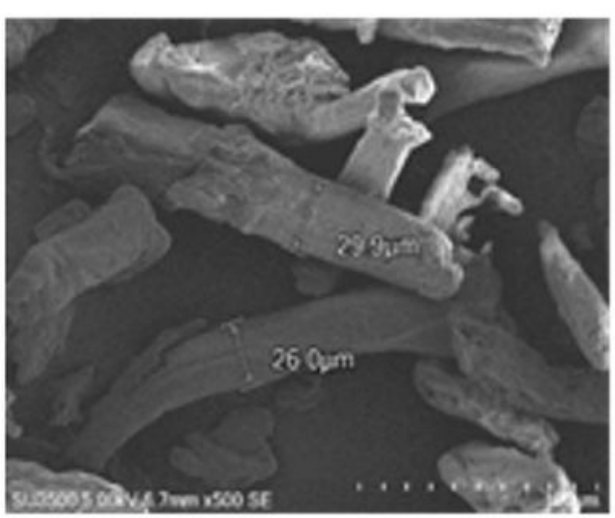

(a)

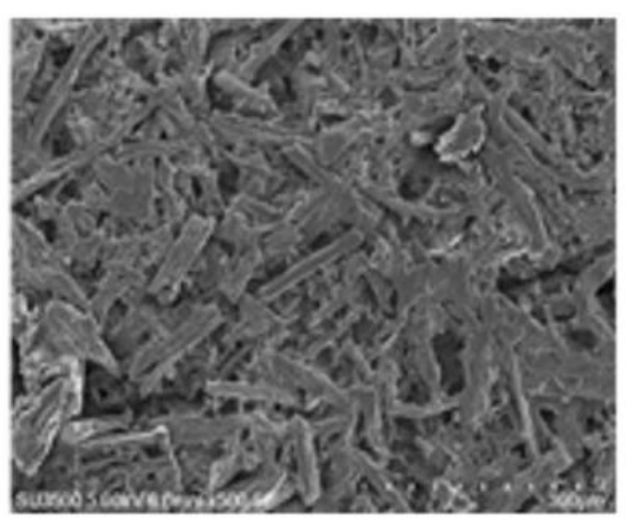

(b)

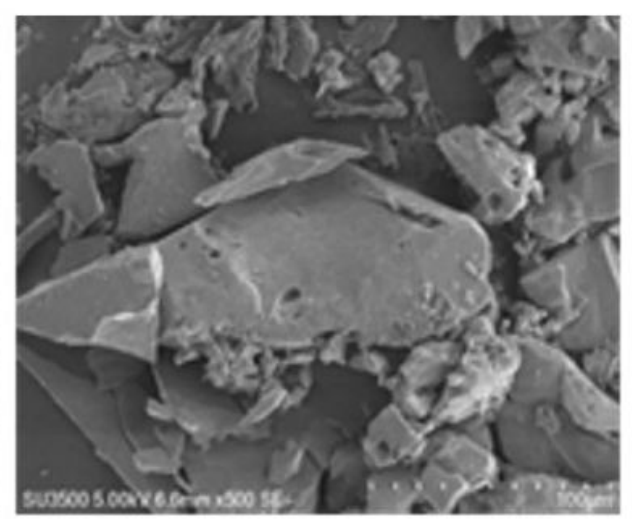

(c)

Figure 5

SEM micrograph for commercial cellulose (a), cajuput twigs CA (b), and sugarcane bagasse CA (c) 


\section{Supplementary Files}

This is a list of supplementary files associated with this preprint. Click to download.

- Graphicalabstract11Jun21.docx 